\title{
Treatment of drilling wastewater using a weakly basic resin
}

\author{
Lü Ronghu* , Mu Bo, Zhang Hongyan and Guo Shaohui \\ School of Chemical Science \& Engineering, China University of Petroleum, Beijing 102249, China
}

\begin{abstract}
Macroporous weak basic anion exchanger (D301R) was used to remove organic substances from drilling wastewater. The effect of $\mathrm{pH}$, temperature and contact time on adsorption behavior was investigated in batch experiments, which indicated that the COD (Chemical Oxygen Demand) removal ratio of drilling wastewater was approximately $90 \%$, and the COD of treated wastewater was below $70 \mathrm{mg} / \mathrm{L}$ under appropriate operating conditions. A mixed liquor of $\mathrm{NaOH}$ and $\mathrm{NaCl}$ was selected as desorbent because of its better elution performance. The results of column dynamic adsorption and regeneration showed that the COD of wastewater could be efficiently removed by D301R resin, and the resin was easily regenerated by the selected desorbent.
\end{abstract}

Key words: Ion-exchange, drilling wastewater, weak basic anion resin, wastewater treatment

\section{Introduction}

A large amount of wastewater is produced during drilling operation. There are primarily three components, namely waste drilling fluid, flushing water and cooling water from equipment, and a small amount of lube from drill outfit. Of these waste drilling fluid is assuredly the main contaminant (Zhu and Xiong, 1999).

A large amount of mineral, micromolecular organics and macromolecular additives exist in drilling wastewater, and form a complicated stable multilevel wastewater system which includes suspended substances, colloidal sol and macromolecular compounds. There are several mature methods used in industry for treating drilling wastewater, such as the coagulation method ( Li et al, 2003b) and the microbiological method (Xiao et al, 2006), but their performance is not satisfactory. In most cases, a high COD removal ratio can be achieved when drilling wastewater is treated by these methods, but it is difficult for COD of final effluent to meet the discharge standard (i.e. COD $<100 \mathrm{mg} / \mathrm{L}$ ). The coagulation-adsorption method, using active carbon as the sorbent, is satisfactory to meet the discharge standard, but regeneration of the sorbent is difficult (Lü and Jiang, 2002). The reason is that the organic pollutants in drilling wastewater, which mostly come from drilling mud additives, contain highly water-soluble organic groups such as sulfonics and carboxylics (Zhang et al, 2007). It is difficult to treat these substances by conventional methods. Hence, it is necessary to find a more effective method to lower the COD of final effluent. Ion exchange resin exhibits good sorption characteristics for ionic organic compounds, such as sulfonate and naphthalene sulfonate (Chai et al, 2005). Hence, in this

* Corresponding author. E-mail: lurh@cup.edu.cn Received December 30, 2007 work, ion-exchange using D301R resin was employed to treat drilling wastewater, which had first been pretreated by the coagulation method. The result showed that this method was suitable for treating drilling wastewater.

\section{Experimental}

\subsection{Material, method and apparatus}

The drilling wastewater used in this experiment was obtained from an oilfield in eastern Sichuan, southwest China. After being treated by the conventional coagulation method, the wastewater was dark brown and had a COD of 600-650 and $\mathrm{pH}$ of 7-8. The macroporous weakly basic anion exchanger, D301R, was from the chemical plant of Nankai University, Tianjin, China. Its physical properties and specifications are shown in Table 1. All the reagents, such as sodium hydroxide and hydrochloric acid were of analytical grade.

A thermostated shaker bath (HZS-H, Harbin Donglian Electronic \& Technology Development Co. Ltd, China) was used to conduct the batch sorption experiment. A peristaltic pump (BT01-100, Hebei Longer Pump Precision Co. Ltd, China) was used to control flow rate in column experiments, and the glass column used was self-made (height $=35 \mathrm{~cm}$; diameter $=1.2 \mathrm{~cm}$ ). An ultraviolet spectrometer (UV160A, Shimadzu Co., Japan) was used to determine ultraviolet absorbency. The pH measurements were conducted with a pH-meter (PH-HJ90B, Shanghai Precision \& Scientific Co., Ltd, China), and COD analyses were carried out with the dichromate method (GB 11914-89, Water qualityDetermination of chemical oxygen demand-Dichromate method, China).

\subsection{Procedure}

The resin was first soaked in a $10 \mathrm{~g} / 100 \mathrm{~mL} \mathrm{NaCl}$ solution 
Table 1 Characteristics of the macroporous weak basic anion exchanger D301R

\begin{tabular}{cccccc}
\hline Resin & $\begin{array}{c}\text { Matrix } \\
\text { structure }\end{array}$ & Type & $\begin{array}{c}\text { Functional } \\
\text { group }\end{array}$ & $\begin{array}{c}\text { Moisture content } \\
\text { wt \% }\end{array}$ & $\begin{array}{c}\text { Total exchange capacity } \\
\text { mmol/mL (wet resin) }\end{array}$ \\
\hline \multirow{2}{*}{ D301R } & Styrene-DVB & Macroporous & $-\mathrm{N}\left(\mathrm{CH}_{3}\right)_{2}$ & $50-60$ & 1.4 \\
\hline
\end{tabular}

for $24 \mathrm{~h}$. After it swelled, the resin was washed clean with distilled water, and then it was put into a beaker and was alternately treated with $1 \mathrm{~mol} / \mathrm{L} \mathrm{NaOH}$ and $\mathrm{HCl}$ solutions several times. Finally, it was washed with distilled water until the effluent liquid was neutral.

Batch experiments: $100 \mathrm{~mL}$ of wastewater was put in contact with $1 \mathrm{~mL}$ of wet resin in a conical flask (150 $\mathrm{mL})$. The flasks were shaken in a thermostat shaker bath. The temperature, contact time, $\mathrm{pH}$, resin dosage being changed respectively. Upon reaching equilibrium, samples were withdrawn to measure the COD at regular intervals. The selection of desorbents was also conducted by batch experiments. $1 \mathrm{~mL}$ saturation adsorbed resin was put in $50 \mathrm{~mL}$ different desorbents $(\mathrm{NaOH}, \mathrm{NaCl}$, or $\mathrm{NaOH} / \mathrm{NaCl})$ which had the same ion concentration and kept for one hour. Then the Ultraviolet (UV) absorbency $(\lambda=203 \mathrm{~nm})$ of the aqueous phase was determined.

$$
\text { COD removal }=\left(C_{0}-C\right) / C_{0} \times 100 \%
$$

where $C_{0}$ is the COD $(\mathrm{mg} / \mathrm{L})$ of the raw wastewater; $C$ is the $\mathrm{COD}(\mathrm{mg} / \mathrm{L})$ of resin-treated wastewater.

Column experiments: A column filled with $10 \mathrm{~mL}$ resin was fed with $1.8 \mathrm{~L}$ wastewater at a specific flow rate. The COD of the effluent was regularly measured. Based on the most appropriate operating condition obtained in batch experiment, the flow rate was taken into account as the influence factor.

For regeneration of the resin, a desorbent was first selected by batch experiment (as mentioned above), and then the effects of flow rate and concentration of the desorbent on regeneration of the resin were investigated by measuring UV absorbency $(\lambda=203 \mathrm{~nm})$ of eluent.

\section{Results and discussion}

\subsection{Batch experiment results}

\subsubsection{Effect of $\mathrm{pH}$}

Fig. 1 presents the effect of the initial $\mathrm{pH}$ of wastewater on the removal of COD by D301R. The volume of wastewater was $100 \mathrm{~mL}$ at $25^{\circ} \mathrm{C}$ the dosage of resin was $1 \mathrm{~mL}$, and the contact time was $8 \mathrm{~h}$. It is clear that the resin is more effective when $\mathrm{pH}<4$. The lower the $\mathrm{pH}$ of the wastewater, the lower the COD would be. It is concluded that a lower $\mathrm{pH}$ of wastewater is good for adsorption and exchange by D301R. This result is in accordance with the protonization process of weakly basic resin (Bhandari et al, 1992), which assumes that the active functional group on resin should first be protonized before adsorption, and then followed by the complete dissociation of the acid anions from the protonated ionogenic species of the resin. In order for the resin to adsorb acid anions, there should be sufficient acidity in the solution (Li et al, 2003a). According to the result, the most suitable $\mathrm{pH}$ of the wastewater is 2 .

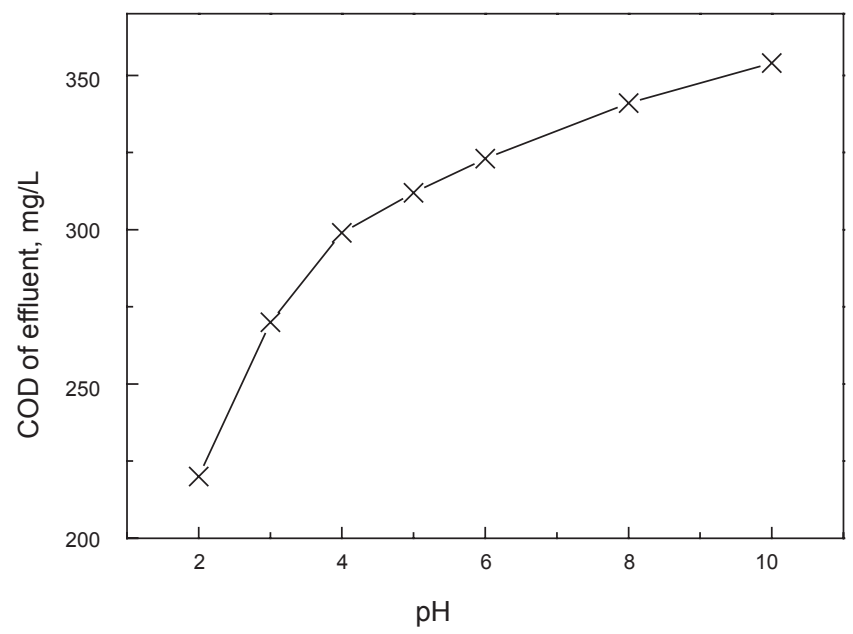

Fig. 1 Effect of $\mathrm{pH}$ on removal of COD by D301R resin

\subsubsection{Effect of temperature}

The effect of temperature is shown in Fig. 2. The volume of wastewater was $100 \mathrm{~mL}$, the dosage of resin was $1 \mathrm{~mL}$, and the $\mathrm{pH}$ of wastewater was 2 , the contact time was 8 h. From Fig. 2, the adsorption capacity of resin at $45^{\circ} \mathrm{C}$ is superior to others, indicating that this adsorption process is endothermic and that the amount of COD adsorbed increases with increasing temperature (Long et al, 2004). But when the temperature was higher than $25^{\circ} \mathrm{C}$, the difference in COD removal ratio was negligible $(<4 \%)$ and in view of energy conservation, room temperature $\left(25^{\circ} \mathrm{C}\right)$ was selected as the appropriate temperature.

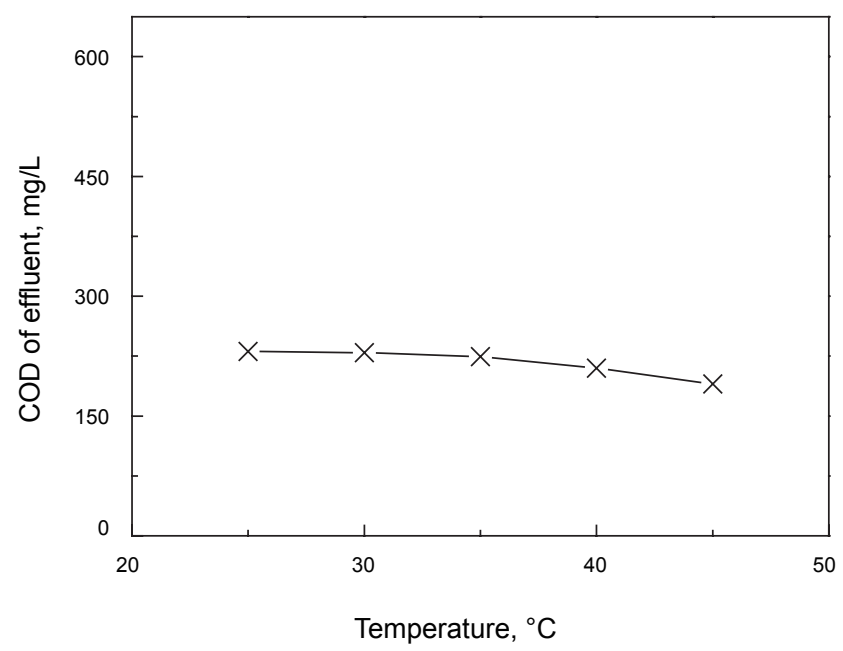

Fig. 2 Effect of temperature on removal of COD by D301R resin 


\subsubsection{Effect of contact time}

Fig. 3 shows the effect of contact time on the removal of COD by the D301R resin. The dosage of resin was $1 \mathrm{~mL}$, the volume of wastewater was $100 \mathrm{~mL}$ at $25^{\circ} \mathrm{C}$ and the $\mathrm{pH}$ of wastewater was 2 . It is clear that the COD of effluent decreased with time and did not change after $5.5 \mathrm{~h}$, so it could be considered that adsorption equilibrium was reached and the resin was saturated within $5.5 \mathrm{~h}$.

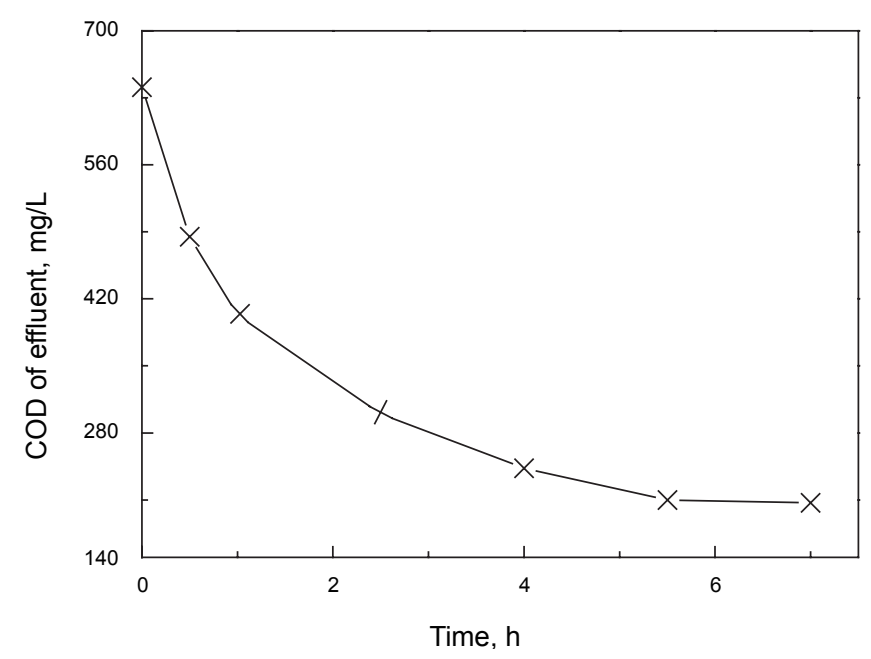

Fig. 3 Effect of contact time on removal of COD by the D301R resin

\subsubsection{Effect of resin dosage}

Fig. 4 shows the effect of resin dosage on the removal of COD by the D301R resin under the optimum operating conditions of $\mathrm{pH} 2$, temperature $25^{\circ} \mathrm{C}$ and contact time 5.5 $\mathrm{h}$. It indicates that the COD of the effluent decreased with increasing resin dosage, but it did not change after the resin dosage was equal to and more than $2.0 \mathrm{~mL}$, i.e. the ratio of resin/wastewater equal to or more than $1 / 50$. Under such conditions, the COD removal ratio could reach $90 \%$ with CODmin of effluent of $65 \mathrm{mg} / \mathrm{L}$, and the effluent water became colorless and clear.

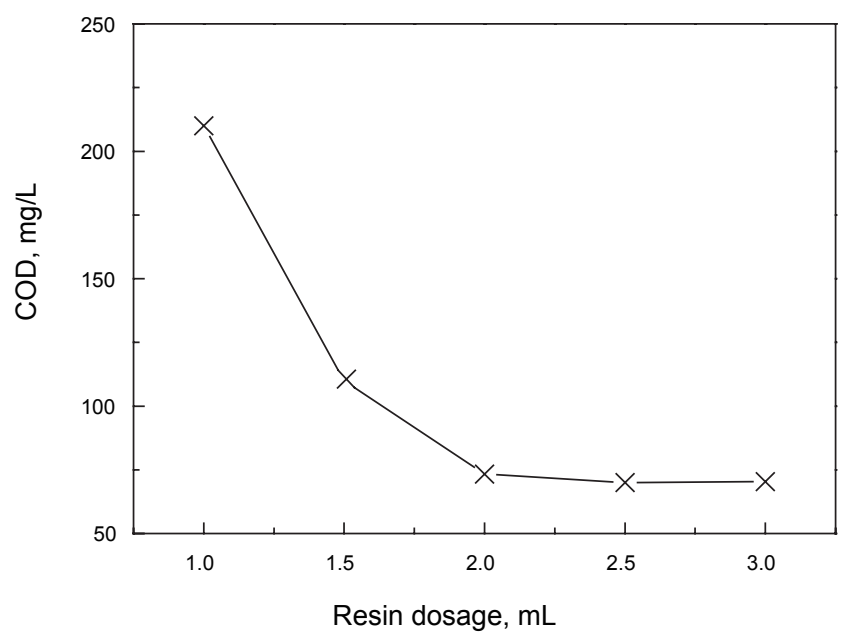

Fig. 4 Effect of resin dosage on the removal of COD by the D301R resin

\subsubsection{Selection of desorbent}

The eluent had a characteristic UV absorption peak, as Fig. 5 shows, with a wavelength of $203 \mathrm{~nm}$. The UV absorbency at this wavelength reflects the concentration of organic substances in the eluent.

Three desorbents $\mathrm{NaOH}, \mathrm{NaCl}$, and $\mathrm{NaOH} / \mathrm{NaCl}$ (V/ $\mathrm{V}, 1 / 6)$, all with an anion concentration of $1 \mathrm{~mol} / \mathrm{L}$, were separately used for the experiments. These experiments were carried out at $25^{\circ} \mathrm{C}$, and $1 \mathrm{~mL}$ of saturation adsorbed D301R resin was put in $50 \mathrm{~mL}$ of each desorbent for $1 \mathrm{~h}$, and then the UV absorbency of the eluent was measured. The results are shown in Table 2. Table 2 shows that the UV absorbency of the eluent of three desorbents was in the order of $\mathrm{NaOH} / \mathrm{HCl}$ $(\mathrm{V}: \mathrm{V}, 1: 6)>\mathrm{NaCl}>\mathrm{NaOH}$, indicating that $\mathrm{NaOH} / \mathrm{HCl}(\mathrm{V}: \mathrm{V}$, $1: 6)$ has the largest desorption capacity. This phenomenon could be explained by that the resin has different swelling capacity in different ion solutions (Xu, 1996). The $\mathrm{NaOH} /$ $\mathrm{NaCl}$ solution contains two different anions, which were dispersed in D301R resin and made resin shrink and expand constantly, and created a compression force that was favorable for macro-molecular organic substances to escape from the D301R resin (Qian and Liu, 1984). So $\mathrm{NaOH} / \mathrm{NaCl}$ solution was selected as the desorbent in the experiment.

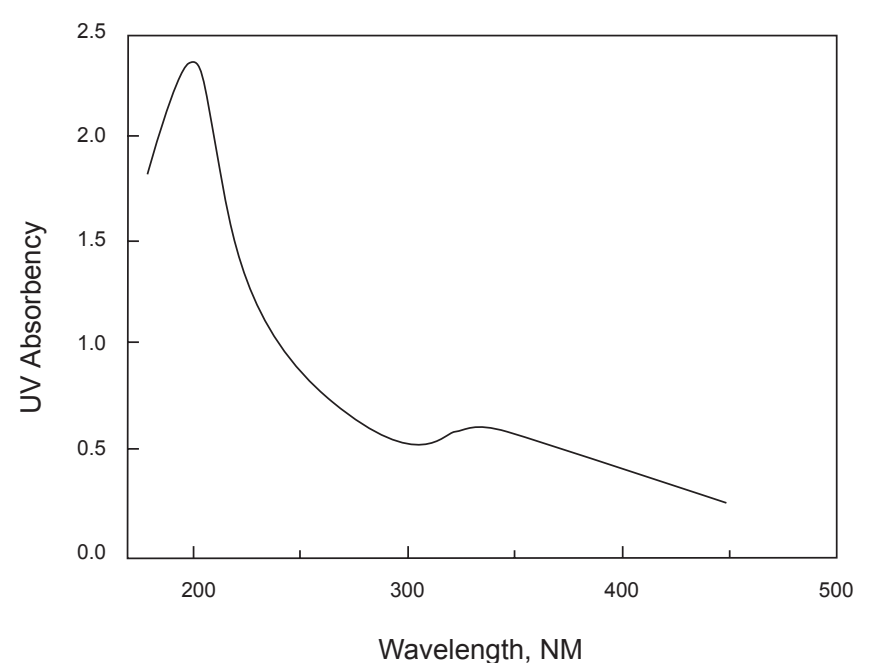

Fig. 5 UV spectea of the eluent

Table 2 Desorption capacity of different desorbents

\begin{tabular}{cccc}
\hline Desorbent & $\mathrm{NaOH}$ & $\mathrm{NaCl}$ & $\begin{array}{c}\mathrm{NaOH} / \mathrm{NaCl} \\
(\mathrm{V} / \mathrm{V}, 1 / 6)\end{array}$ \\
\hline UVA $\lambda=203$ & 1.123 & 1.808 & 2.197 \\
\hline
\end{tabular}

Notes: The ion concentration of all three desorbents was $1 \mathrm{~mol} / \mathrm{L}$

\subsection{Column experiment results}

Adsorption dynamics is an important aspect in evaluating resins for technical use. Therefore, dynamic adsorption curves and stripping curves for drilling wastewater were determined in experiments. 


\subsubsection{Effect of flow rate on dynamic adsorption}

Drilling wastewater (under the optimum adsorption conditions of $\mathrm{pH} 2$ and at room temperature) flowed through the column. Fig. 6 presents the dynamic adsorption curves at different flow rates. The Chinese national standard for effluent discharge $(\mathrm{COD}<100 \mathrm{mg} / \mathrm{L})$ was used as breakthrough point. Fig. 6 shows that the breakthrough volume decreased with increasing flow rate, but their throughput $(\mathrm{COD}<100 \mathrm{mg} / \mathrm{L})$ did not change greatly in the flow rate range of 4-6 BV(bed volume). Considering the throughput of the resin per unit time, $6 \mathrm{BV} / \mathrm{h}$ was selected as the appropriate flow rate in this experiment.

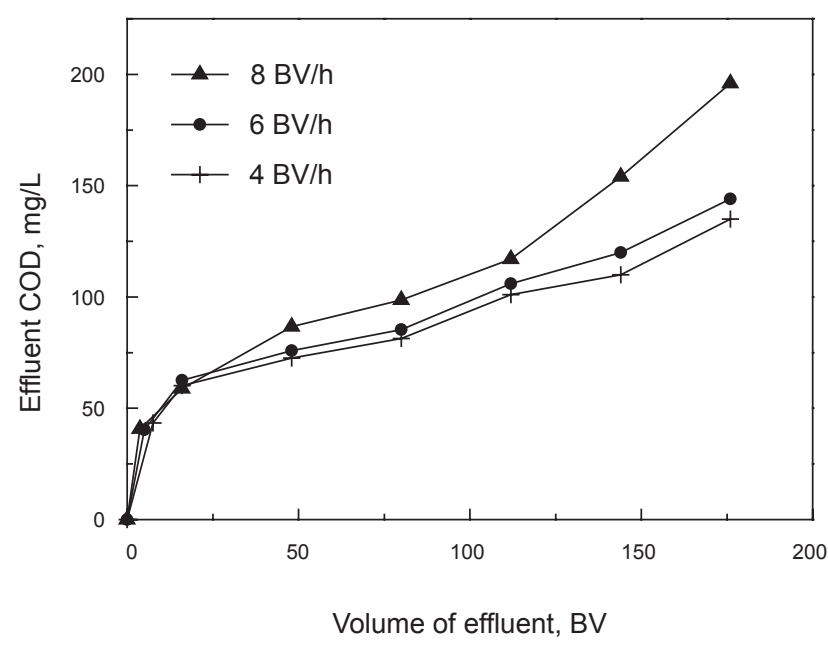

Fig. 6 Effect of flow rate on dynamic adsorption curves

\subsubsection{Effect of desorbent concentration on regeneration of D301R resin}

The D301R resin was regenerated after the adsorption process by using the selected desorbent $\mathrm{NaOH} / \mathrm{NaCl}(\mathrm{V} / \mathrm{V}$, 1/6). The effect of desorbent concentration on regeneration of D301R resin is shown in Fig. 7. When the concentration of desorbent was high, the stripping curve was acute and narrow,

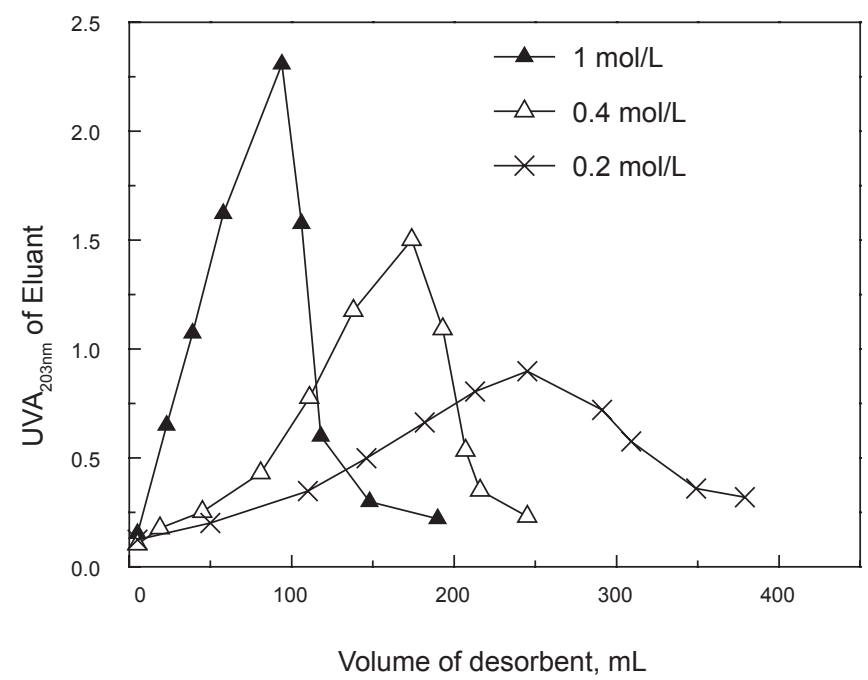

Fig. 7 Effects of concentration of desorbent on regeneration of D301R resin and there was no lingering. On the contrary, the lower the concentration of desorbent, the more desorbent was required, and the peak widened with a worse lingering line. Hence, a high concentration of desorbent $(1 \mathrm{~mol} / \mathrm{L})$ is favorable to regeneration of D301R resin. Fig. 7 Effects of concentration of desorbent on regeneration of $\mathrm{D} 301 \mathrm{R}$ resin.

3.2.3 Effect of desorbent flow rate on regeneration of D301R resin

Fig. 8 shows the effects of different flow rates of desorbent on regeneration of the $\mathrm{D} 301 \mathrm{R}$ resin. When the flow rate is low, i.e. $4 \mathrm{BV} / \mathrm{h}$, the stripping curve is acute and narrow. When the flow rate changes from 4 to $8 \mathrm{BV} / \mathrm{h}$, the peak does not change so greatly as flow rate does. That is because the elution process is usually of particle diffusion control (PDC) (Jiang et al, 1992), and the effect of desorbent flow rate on regeneration of the D301R resin could be ignored. Thus, a lower flow rate $(4 \mathrm{BV} / \mathrm{h})$ could be used for the regeneration of the resin.

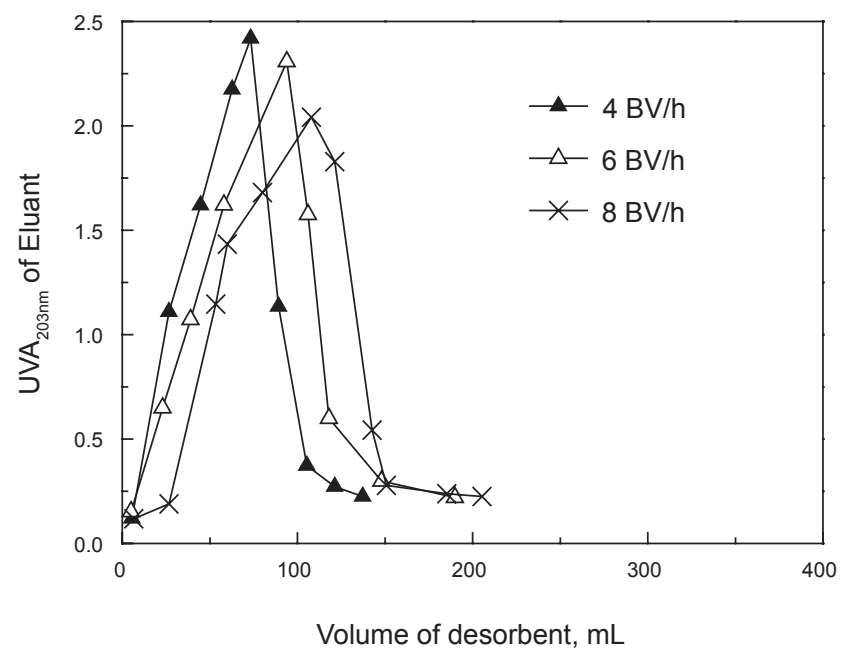

Fig. 8 Effect of flow rate of desorbent on regeneration of D301R resin

\section{Conclusions}

It is feasible to remove the organic pollutants from drilling wastewater by using macroporous weakly basic anion exchange resin D301R, and the COD removal ratio could reach $90 \%$. As the batch experiments showed, a higher temperature and a lower $\mathrm{pH}$ were good for adsorption and exchange. The column experiments indicated that the favorable flow rate was $6 \mathrm{BV} / \mathrm{h}$. Also, a mixed liquor of $\mathrm{NaOH}$ and $\mathrm{NaCl}$ with a high anion concentration and a low flow rate could achieve good resin regeneration.

\section{References}

Bhandari V M, Juvekar V A and Patwardhan S R. Sorption studies on ion exchange resins-1. Sorption of strong acids on weakly base resins. Ind. Eng. Chem. Res. 1992. 31: 1060-1073

Chai L M, Zhang F B and Zhang G L. Treatment of DSD acid wastewater using a weakly basic resin. Desalination. 2005. 180: $157-162$ 
Jiang Z X., Chen J Q and Song Z X. Ion exchange and separation engineering. Tianjin: Tianjin University Press. 1992. p79 (in Chinese)

Li C H, Li Y Z and Hua X Y. Treatment of CLT acid waste water based on weakly basic resin. Ion Exchange and Adsorption. 2003a. 19(6): 511-516 (in Chinese)

Li Y, Xia S L, Zhang J M, et al. Laboratory experimental study on drilling wastewater treatment by coagulation and centrifugalization. Oilfield Chemistry. 2003b. 20(3): 277-284 (in Chinese)

Long C, Zhang Q X and Chen J L. Adsorption of highly water-soluble aromatic sulfonic acids onto macroporous weakly basic anion exchanger. Applied Chemistry. 2004. 21(10): 998-1000 (in Chinese)

Lü R H and Jiang W Y. Treatment of drilling wastewater correlated with three-sulfonated mud system by coagulation-adsorption process. Environmental Engineering. 2002. 3-5 (in Chinese)

Qian T B and Liu W L. Rejuvenation of ion exchange resin polluted by organic substances. Technology of Water Treatment. 1984.10(3): 41-44 (in Chinese)

Xiao L L, Huo D Q, Qin L, et al. Treatment of petroleum pollutants from drilling wastewater by microbiological method. Industrial Water Treatment. 2006. 26(4): 59-65 (in Chinese)

Xu L F. Rejuvenation mechanism of anion exchange resin. North China Electric Power. 1996. 9: 16-21 (in Chinese)

Zhang H Y, Lü R H and Guo S H. Treatment of drilling wastewater correlated with three-sulfonated mud system by coagulation-ozone oxidation process. The Chinese Journal of Process Engineering, 2007. 7(4): 718-722 (in Chinese)

Zhu Q Y and Xiong C P. Discussion on technology and equipment to dispose drilling wastewater. Environmental Protection of Oil and Gas Fields, 1999. 9(2): 34 (in Chinese)

(Edited by Zhu Xiuqin) 